Revista de Dialectología y Tradiciones Populares, vol. LXX, n. ${ }^{\circ}$ 2, pp. 277-290, julio-diciembre 2015,

ISSN: 0034-7981, eISSN: 1988-8457, doi: $10.3989 /$ rdtp.2015.02.001.02

\title{
La economía moral del asilo. Reflexiones críticas sobre la "crisis de los refugiados" de 2015 en Europa
}

\author{
The Moral Economy of Asylum. \\ Critical Reflections on the 2015 "Refugee Crisis" in Europe
}

\author{
Didier Fassin \\ James D. Wolfensohn Professor of Social Science \\ Institute for Advance Studies, Princeton University
}

\section{RESUMEN}

Este artículo plantea una reflexión crítica sobre la llamada "crisis de los refugiados" de 2015 en Europa a partir de una reformulación del concepto de economía moral que problematiza discursos y prácticas de asilo. Propone primero una concepción histórica del uso y significado de las categorías de refugio y asilo que nos permita además explorar los cambios en la representación de los individuos involucrados y en la legitimidad social de sus reivindicaciones. Para ello se analiza la evolución del derecho al asilo en Europa desde una multiplicidad de lentes —etimológica, histórica y geográfica- como preámbulo al estudio de su declive en las últimas décadas. El artículo concluye que las decenas de miles de personas que cruzan el Mediterráneo desde África y el Oriente Medio en búsqueda de protección no han creado una "crisis", sino que revelan una situación que ya existe desde hace varias décadas: el retiro progresivo de los países europeos de sus compromisos adquiridos con la Convención de Ginebra de 1951.

Palabras clave: Asilo; Economía moral; Europa; Francia; Convención de Ginebra.

\section{SUMMARY}

Based on a reformulation of the classical concept of Moral Economy that problematizes discourses and practices of asylum, this paper poses a critical reflection of the so-called 2015 European "Refugee Crisis". It first proposes a historical scrutiny of the uses and meanings of the categories of refuge and asylum, which creates the analytical context to explore the transformations in the representations of the individuals involved in migratory movements as well as the social legitimacy of their claims. In order to do so, the paper analyzes the evolution of the right of asylum in Europe from a multiplicity of lenses —etymological, historical, geographical — as a preamble to the study of its decline in the last decades. The paper concludes that the tens of thousands of people crossing the Mediterranean 
from Africa and the Middle East, searching for protection, have not created any "crisis", but rather reveal to the public eye a situation that has already existed for many decades: the progressive withdrawal of European countries from the commitments acquired when signing the 1951 Geneva Convention.

Key words: Asylum; Moral Economy; Europe; France; Geneva Convention.

La crisis de refugiados en Europa se ha caracterizado en los últimos meses por dos hechos principales. Uno cuantitativo, el otro cualitativo. El primero tiene que ver con las 340.000 personas que han atravesado las fronteras de la Unión Europea (UE) este año, la mayoría desde Siria. La cifra puede imponer, pero se relativiza cuando la comparamos a los 500 millones de habitantes de la UE (siendo que los recién llegados serían menos de uno entre mil), a las cifras en el Medio Oriente (en Líbano un millón cien mil refugiados sobre una población de casi 4 millones y medio, casi 400 veces más alta), o simplemente a las estadísticas diez años atrás (casi 300.000 sólo de peticionarios de asilo en 2004 en Europa). El segundo fenómeno tiene que ver con el modo en que se denomina a los que cruzan estas fronteras. Todavía hace unos pocos meses, prevalecía la calificación de inmigrantes y se les veía como extranjeros ilegales. Todo lo más, uno podría expresar compasión por un barco que hubiera naufragado causando cientos de muertos, pero era más común el discurso de la represión de los traficantes y del control de las fronteras. Recientemente ha ocurrido una transformación semántica: se habla de refugiados y se considera que pueden estar buscando asilo. Aunque el léxico del rechazo, la violencia y la coacción no ha desaparecido, el del derecho a la protección aparece y la gente tiene la posibilidad de solicitar asilo. Sin embargo, eso vale sobre todo cuando nos referimos a los que llegan desde Siria, porque con los procedentes de Somalia, Eritrea o Sudán no es tan claro, siendo que existe sin duda una dimensión racial en este reconocimiento selectivo.

Estas dos tendencias representan bien los dos temas generales que quiero tratar en este ensayo: cómo la cuestión de los refugiados y los contornos del asilo se reconfiguran permanentemente, y cómo estas transformaciones son mayormente causadas o al menos asociadas con cambios en la representación de los individuos involucrados y en la legitimidad de sus reivindicaciones. No se trata tanto de que las situaciones de las personas víctimas de persecución o violencia sean diferentes, sino que son los valores y los afectos que generan esas situaciones los que cambian con el tiempo. Para interpretar este fenómeno, propongo reformular el concepto de economía moral.

Como es bien conocido, esta expresión fue acuñada por E.P. Thompson en su monografía sobre la clase obrera inglesa (1968), y analizada con más precisión en su replanteamiento de la relevancia de los llamados disturbios del hambre (1971): la economía moral del proletariado o del campesinado era para él el conjunto de normas y obligaciones, prácticas de solidaridad y expectativas de justicia que estaban en vigor en esos mundos, y que en su visión se oponía a una economía de mercado implícitamente inmoral. El concepto se exportó a las ciencias políticas y a la antropología cultural a través de James Scott (1976). Lo que probablemente se conoce menos es que se redescubrió veinticinco años después por Lorraine Daston, que lo utilizó para analizar el mundo de los científicos del siglo XVII (1995). La economía moral de la ciencia era para ella una red de valores y afectos intrínsecos en la práctica y ethos científicos. La nueva versión tuvo influencia en los estudios sociales de la cien- 
cia y en la antropología médica. Así pues, para Thompson la economía era el concepto más importante en la expresión 'economía moral', mientras que para Daston, la moral era el elemento definitorio. Pero ambos consideraban que las economías morales caracterizaban un determinado mundo - el del campesinado o el de los científicos-, lo cual tenía dos implicaciones: primero, se arraigaba en un tipo de cultura, cultura económica del campesinado o cultura intelectual de los científicos; y segundo, asumía un conjunto relativamente permanente de valores, con una cierta estabilidad a través de los siglos.

Para evitar la inclinación culturalista y dar una perspectiva más dinámica al concepto, he propuesto adaptar la definición clásica de economía política (Say 1972), y definir las economías morales como la producción, circulación y apropiación de normas y obligaciones, valores y afectos relativos a un problema específico en un tiempo y espacio específicos (Fassin 2009). Cuando digo problema me refiero al sentido foucaultiano de lo que es problematizado (Foucault 2001), en otras palabras, lo que se formula como un problema, el modo en que es interpretado y abordado. No hablamos por tanto de la economía moral de un grupo o de una actividad social, sino de una temática social, como el abuso infantil, el castigo, la inmigración o, en este caso, el asilo.

Lo que por tanto intentaré hacer es reflexionar sobre la cuestión de los refugiados y el problema del asilo a través del concepto de economía moral tal y como lo he redefinido — con la esperanza de que tenga un valor heurístico más allá de esta cuestión específica.

\section{EL ASILO A TRAVÉS DE LENTES MÚLTIPLES}

\section{ETIMOLOGÍA}

Se asume que el origen del concepto de asilo se encuentra, tanto histórica como etimológicamente, en el espacio protegido de los templos griegos (de "sulon", derecho de amparo): los sacerdotes inventaron el principio de "asulon" (refugio) para protegerse de invasores y guerreros. Traducido al Latin como "asylum" (santuario), el concepto adquirió un sentido muy diferente, designando un espacio seguro fuera de la ciudad donde podían escapar de la justicia y el castigo criminales, parias, esclavos y -importante para nuestra interpretación contemporánea- oponentes políticos: eran lugares inviolables (Fustel de Coulanges 1900:182). Tanto la noción griega como la romana remiten a lo sagrado, es decir, una separación, en estos casos física, del mundo profano: marcan un espacio de excepción. Pero de un mundo a otro los beneficiarios de este lugar sagrado pasó de lo religioso/sacerdotal a lo social/político.

Más allá de este origen literal, la genealogía de lo que hoy entendemos como asilo se arraiga también en otra tradición, la de la hospitalidad. La investigación filológica de este concepto revela una ambigüedad relevante pues la palabra viene de hospes, huesped, a su vez de la raíz hostis, el enemigo, origen del concepto hostilidad (Benveniste 1969:87). Ambos términos refieren así pues al extranjero, que puede ser visto bajo una luz favorable o perjudicial, y que se distingue de un tercer término, peregrinus, que designó inicialmente a un sujeto libre de provincias que no era ciudadano romano, y que luego se refirió a todos los extranjeros, con excepción de los 
bárbaros: se establece por tanto una interesante distinción entre extraños, como potenciales huéspedes, y extranjeros, como no ciudadanos, retringiendo la relación de equidad y reciprocidad al primero.

Considerando esta semántica dual así como el legado historiográfico, tenemos entonces dos verdades fundamentales del asilo contemporáneo: el sagrado derecho a protección en un espacio inviolable, independiente de la condición del refugiado per se, y la ambivalencia de la hospitalidad, siempre en peligro de hostilidad.

\section{HISTORIA}

El sentido moderno de asilo, tal y como va emergiendo al final del siglo XVIII, y con mayor fuerza a partir de la primera guerra mundial, está configurado por dos factores: uno demográfico y otro político. Por una parte, el asilo tiende a referirse no sólo ya a individuos o grupos de individuos. Abarca miles y en ocasiones millones de potenciales refugiados: rusos huyendo del régimen comunista, armenios intentando escaparse de las masacres de los turcos, republicanos perseguidos por el Nacional Catolicismo español, judíos acorralados por los Nazis, y finalmente, masas inmensas de personas desplazadas después de la segunda guerra mundial. Por otra parte, el asilo no corresponde ya a las ciudades, sino a los estados, donde la lógica de la protección universal compite con la lógica de la soberanía nacional. En este nueva configuración, un control crecientemente burocrático se ejerce sobre los que intentan cruzar fronteras: la distinción entre inmigrantes y refugiados vuelve a ser problemática.

La ratificación de la Convención de Ginebra, el 28 de julio de 1951, precedida por la creación del Alto Comisionado para los Refugiados, y seguido por el establecimiento de cuerpos específicos encargados de la regulación práctica del asilo en la mayor parte de los países, dio un contexto legal y una red institucional para abordar estas dos cuestiones de cifras y estados. La aún incompleta reconstrucción histórica de las negociaciones que llevaron a la firma de este importante texto de la ley internacional, nos revela que en las bambalinas de la preparación del acuerdo, los gobiernos fueron mucho menos generosos de lo que la mítica narrativa de los orígenes de este acuerdo nos ha hecho pensar (Noiriel 1991). Sin embargo, las expectativas y esperanzas eran tan altas que el más conocido cronista de la saga de refugiados en Europa concluyó su libro profetizando el "fin aparente del problema del refugio" (Marrus 1985:371) —algo que debería bajar los humos a cualquier científico social con tendencias proféticas. El retorno de este "problema" no es, sin embargo, una mera repetición de lo que sucedió al final de la segunda guerra mundial. Lo que hoy lo caracteriza no tiene precedentes: es un síntoma del mundo contemporáneo, más que de la idiosincrasia del asilo propiamente dicho.

\section{GEOGRAFÍA}

Bajo la Convención de Ginebra de 1951, un refugiado es «aquella persona que, debido a fundados temores de ser perseguido por razones de raza, religión, nacionalidad, membresía de un grupo social o de opinión política en particular, se encuen- 
tra fuera de su país de nacimiento y no pueda o a causa de dichos temores no esté dispuesto a servirse de la protección de aquel país" (UNHCR/ACNUR 2011). Pero la Convención, aunque no se suele reconocer, se limitaba en su ámbito de actuación a las víctimas de los "sucesos que ocurrieron antes del 1 de enero de 1951", lo cual significa que se refería exclusivamente a los europeos víctimas de la segunda guerra mundial. Sólo en 1967 el Protocolo de Nueva York, "considerando que es deseable que todos los refugiados tengan el mismo estatus", se generalizó la protección a cualquier persona que de hecho esté en la situación que indica la definición del término. Pero pronto resultó evidente que la globalización del asilo, con su ambición de trato justo a todas las víctimas, asumía un patrón profundamente asimétrico y desigual. Para decirlo claramente: en el sur están los refugiados, en el norte los solicitantes de asilo. No se trata simplemente de una cuestión de vocabulario ni siquiera de estatus. Es una diferencia de régimen de reconocimiento.

Hay dos configuraciones distintas relacionadas con esta definición. La primera, que encontramos fundamentalmente en sur global, es la de hombres y mujeres que huyen de la violencia a un país vecino donde por lo general se les agrupa en campos de refugiados: esta es la situación de cientos de miles de refugiados de Afganistán en Pakistán e Irán, del Congo en Burundi y Ruanda, o de Somalia en Kenia. La segunda, que encontramos por lo general en el norte global, corresponde a hombres y mujeres que solicitan protección de los países de Norteamérica o Europa Occidental a través de canales administrativos: esta es la experiencia de decenas de miles de solicitantes de asilo en Francia, Gran Bretaña, Alemania, o los Estados Unidos. En el primer caso, se les considera colectivamente refugiados por el mero reconocimiento de su condición de fugitivos de una zona de guerra o represión. En el segundo, son solicitantes de asilo valorados individualmente a través de procesos inquisitivos, de los cuales sólo una minoría será reconocida con el estatuto de refugiado. También existe una opción intermedia, el reasentamiento, en la que algunos países del norte global establecen cuotas para refugiados en campamentos situados en el sur global, seleccionados con criterios específicos y autorización para inmigrar.

\section{EL DECLIVE DEL ASILO}

\section{VERDAD}

En Francia, la revisión individualizada de las aplicaciones es la única vía para el asilo. Dos instituciones realizan esta selección: la OFPRA, la Oficina Francesa para la Protección de los Refugiados y Apátridas, una instancia administrativa cuyos funcionarios deciden sobre las solicitudes, y el CNDA, el Tribunal Nacional del Derecho de Asilo, una institución jurídica cuyos magistrados se pronuncian sobre los recursos de los solicitantes rechazados.

Considerando lo que conocemos sobre la geopolítica de los conflictos y la opresión, el reconocimiento de los "temores fundados de ser perseguido" parecería un procedimiento relativamente directo, basado en las narrativas de los solicitantes de asilo y en los documentos que aportan. El testimonio de sucesos del pasado (violencia sufrida o amenazas), apoyado en evidencias materiales (pasaporte o carnet de 
identidad que prueben el origen y ciudadanía, artículos de periódicos o procesos judiciales, certificados médicos o psicológicos), avalan la probabilidad de persecución futura si los solicitantes regresaran a sus países de origen. Sin embargo, nunca se puede eliminar totalmente la posibilidad de que los solicitantes mientan cuando cuenten su historia y falsifiquen los documentos que aportan. El examen de su solicitud es por lo tanto una investigación sobre la verdad de la solicitud.

Según la teoría filosófica, hay dos fundamentos con los cuales podría establecerse la verdad: veracidad y sinceridad (Fassin 2013). La veracidad implica una correspondencia objetiva entre los elementos aportados por el solicitante y lo que los funcionarios o jueces saben o imaginan sobre la situación en su país. La sinceridad implica la coherencia subjetiva entre los hechos que se alegan y la personalidad del solicitante tal y como es interpretada durante la entrevista en la OFPRA o en los interrogatorios en el CNDA. Sin embargo, tanto la veracidad como la sinceridad son difíciles de evaluar. Reconocer a un relato como verdadero y a un individuo como fiable requiere cierto nivel de confianza. La evolución más significativa en las políticas de asilo en las últimas décadas ha sido la transformación de la confianza en desconfianza (Daniel y Knudsen 1995). La confianza era la tónica dominante a mediados de la década de los setenta, cuando nueve de cada diez solicitante recibía el asilo. En contraste, la duda parece haberse hecho predominante a mediados de la década de los años 2000, cuando apenas dos de cada diez lo conseguían (OFPRA 2011). ¿Cómo podemos entender esta reducción tan dramática en apenas tres décadas?

\section{JUSTIFICACIONES}

La explicación oficial de esta tendencia es la siguiente. A mediados de los años setenta, el gobierno francés, que enfrentaba un desempleo creciente especialmente entre los trabajadores no cualificados —debido a una combinación de la reconversión industrial y la llamada crisis del petróleo-, decidió cerrar las puertas a la inmigración laboral. Esto hizo que muchos recién llegados al país solicitaran el asilo, que en aquellos momentos parecía la ruta más favorable para obtener documentos. El incremento de solicitantes, que subió desde 2.000 a principios de los setenta hasta 50.000 a principios del siglo XXI, tuvo como consecuencia que las instituciones fueran mucho más estrictas en la evaluación de las solicitudes, supuestamente para distinguir las demandas legítimas de las ilegítimas, cuyos peticionarios fueron denominados "refugiados económicos" o, en el peor de los casos, "falsos refugiados". El descubrimiento de algunos casos de "fraudes de asilo", que tuvieron mucho impacto mediático en los años ochenta, parecían abonar esta interpretación, aunque una investigación sistemática de las huellas dactilares estableció que este engaño sólo afectaba a un 3\% de los solicitantes (OFPRA 2010). Así, de acuerdo con las autoridades, la razón del declive en la concesión de solicitudes de asilo no se derivaba de políticas paulatinamente más restrictivas, sino del hecho de que muchos solicitantes trataran de aprovecharse de la generosidad del sistema. Sin embargo, esta versión oficial del declive de las tasas de admisión tiene dos errores importantes en relación tanto con la situación previa como con la evolución del asilo después de cerrar las fronteras a la inmigración laboral. 
Por un lado, la aparente actitud generosa de los países occidentales en las dos décadas posteriores a la ratificación de la Convención de Ginebra fueron en buena parte consecuencia de dos circunstancias históricas convergentes: la expansión económica vinculada a la reconstrucción de los países europeos tras la Segunda Guerra Mundial, que implicaba la necesidad de fuerza de trabajo, y las tensiones políticas asociadas con la Guerra Fría, que llevó a la recepción de personas que huían de los regímenes comunistas. En este contexto, los refugiados eran bienvenidos y sus contratos laborales servían como permisos de residencia y les evitaban todo el papeleo de la burocracia del asilo; la mayoría de los potenciales solicitantes ni siquiera iniciaron el proceso (Spire 2004). Lógicamente, cuando el flujo de migración laboral se interrumpió, muchos buscaron esta otra vía como refugiados. Así, aunque es posible que algunos inmigrantes económicos se transformaran en buscadores de asilo a mediados de los años setenta, también es cierto que hasta entonces la mayoría de las víctimas de persecución habían tenido suficiente con un contrato laboral.

Por otro lado, a diferencia de lo que la explicación de las autoridades sugiere, la evolución de la flexibilidad de las instituciones a cargo de la concesión del asilo no se corresponde con las fluctuaciones en el número de solicitantes. Independientemente de que haya habido más o menos solicitantes, la tasa de admisión ha decrecido paulatinamente desde 1976, cuando alcanzaron su nivel máximo. Si el rigor en las decisiones de los funcionarios hubiera sido consecuencia de un flujo de inmigrantes que se presentaban de manera fraudulenta como solicitantes de asilo, podría esperarse que cuantas más solicitudes hubiera, más severos habrían sido los funcionarios en su evaluación. Sin embargo la tasa de admisión descendió cinco veces a pesar de un número similar de solicitantes entre 1976 y 1996, y también entre 1986 y 2006. De hecho, 15.000 solicitantes obtuvieron asilo cada año en la década de los ochenta, cuando el número de peticiones estaba en torno a las 20.000. Bajaron a 5.000 en los años noventa, a pesar de que el número de solicitudes era semejante. En otras palabras, el declive se manifiesta no solo en términos de proporción, sino también de cifras absolutas. De este modo, la simple transferencia de inmigrantes económicos al colectivo de buscadores de asilo es altamente improbable.

Resumiendo, el declive se debe en su mayor parte a un cambio en las políticas, que han hecho mucho más estricto el escrutinio de los relatos y documentos de los solicitantes (d'Halluin-Mabillot 2012). No se trata de que las autoridades sean más selectivas porque hay más falsos refugiados, sino que se rechazan más peticiones de asilo y se declaran a más gente como falsos refugiados porque las autoridades son más restrictivas. ¿Cómo interpretar este cambio? Una explicación común es que el creciente control de la inmigración ha llevado a identificar solicitantes de asilo con inmigrantes no deseados. Es cierto, pero para que esta confusión ocurra sin contradicción aparente con la ley, tenía que parecer bien fundamentada. De hecho, las bases morales para esta evolución son consecuencia de un cambio radical que ocurrió a partir del final de los años ochenta en la percepción de los solicitantes de asilo en la sociedad, es decir, en la evaluación de sus peticiones y en las emociones que provocan. 


\section{REPRESENTACIONES}

En las dos décadas que siguieron a la ratificación de la Convención de Ginebra en 1951, la representación de los refugiados estaba dominada por dos figuras principales: en un primer momento, los supervivientes de los campos de la Segunda Guerra Mundial y, después, por las víctimas del comunismo en Europa del Este. Los sentimientos morales que prevalecían era lástima por los primeros, y respeto por las segundas. Estos sentimientos no estaban exentos, como se ha evocado antes, de razones prácticas, con la necesidad de mano de obra, o con motivos ideológicos, en el contexto de la incipiente Guerra Fría. En ese momento, el humanitarismo y el realismo convergían. Hay que recordar que hasta 1967, cuando se ratificó el Protocolo de Nueva York, la protección convencional sólo afectaba a europeos. La construcción de alteridad en este contexto no incluía representaciones raciales, como ocurriría después cuando los solicitantes de asilo empezaran a llegar desde el sur global.

En los años setenta, a pesar del contexto desfavorable propiciado por el cierre de fronteras, dos oleadas de solicitantes de asilo despertaron una amplia simpatía: los luchadores de la resistencia chilena que huían de la dictadura de Augusto Pinochet después del golpe de estado de 1973, y los balseros del sudeste asiático que escapaban de la represión comunista en Vietnam tras la caída de Saigón en 1975. La emoción expresada por gobiernos y por la población hacia su desgracia se mezclaba con admiración en el primer caso, y con compasión en el segundo. De manera significativa, políticos de todos los partidos manifestaron su solidaridad. Llama la atención que ni la interrupción del flujo de la inmigración laboral ni la multiplicación por diez de solicitantes de asilo en esa década supusieron ningún tipo de cortapisa a la expresión de esta flexibilidad. En aquellos años, aunque la inmigración estaba empezando a ser percibida como una amenaza por motivos de empleo y de seguridad, la imagen moral de los refugiados seguía siendo positiva: sus relatos eran raramente cuestionados y su documentación apenas era puesta en duda. En el contexto de una Guerra Fría en declive, Francia y la mayoría de los países europeos todavía trataban de mantener vivo un espacio para los derechos humanos entre los regímenes comunistas y las dictaduras latinoamericanas.

Pero a partir de los años ochenta, la actitud de las autoridades cambió de signo. El contexto nacional e internacional era diferente. En el escenario internacional, la caída del muro de Berlín señaló el final de la división entre el este y el oeste, la Europa de Schengen estaba cada vez más obsesionada con la protección de sus fronteras, y la xenofobia empezó a centrarse en refugiados del sur global. Las políticas de asilo se integraron dentro de programas más amplios de control migratorio de la Unión Europea. En el nivel nacional, el desempleo creciente y la emergencia de la extrema derecha colocaron a los asuntos migratorios en el centro del debate público. Los crímenes racistas se multiplicaron y tuvieron como consecuencia una histórica Marcha por la Igualdad y Contra el Racismo en 1983. Los solicitantes de asilo se fueron asociando con los extranjeros indocumentados en el discurso público de los políticos franceses. En este nuevo contexto, la percepción de los solicitantes de asilo era cada vez más negativa. Sus solicitudes se miraban con desconfianza. Su mundo se percibía como fraudulento. A pesar de todo lo que se sabía sobre la persecución contra los chechenos en Rusia, los tamiles en Sri Lanka o los nativos de Darfur en Sudán, 
los miembros de estos grupos raramente despertaron reacciones emocionales, y la proporción de aquéllos que consiguieron asilo difícilmente excedía al diez por ciento de los solicitantes. Incluso los ciudadanos de Haiti afectados por el terremoto de 2001 que causó un enorme daño en un país que ya sufría de violencia política crónica, o aquéllos que provenían de la República Democrática del Congo, afectados por una guerra civil responsable de tres millones de muertos, según las estimaciones, nunca disfrutaron de la empatía que se manifestó hacia aquellos que habían escapado de situaciones trágicas semejantes en el pasado. La desconfianza dificultó sistemáticamente la expresión de una ola de compasión (Kelly 2012). La representación moral de los solicitantes de asilo parecía estar definitivamente contaminada por la sospecha.

\section{EXCEPCIONES}

Sin embargo, las economías morales son muy raramente homogéneas. Por ejemplo, a medida que las racionalidades clásicas, es decir políticas, religiosas o étnicas, de asilo se fueron desacreditando, hubo dos nuevas categorías morales que escaparon a esta degradación moral: niñas en riesgo de ser sometidas a excisión cuando regresaban a sus países de origen y, por extensión, sus padres; y hombres y mujeres que declaraban que habían sufrido persecución debido a su orientación sexual. En ambos casos, el criterio al que se aludía era el del "grupo social", una categoría judicial abierta extraída del texto de la Convención de Ginebra de 1951. El primer asunto, la circuncisión femenina, fue introducido a través de una serie de decisiones judiciales por parte del Tribunal Nacional del Derecho de Asilo, inicialmente para proteger a las niñas en una decisión de 1991, posteriormente para incluir a sus padres en otra que data de 2001 (Cholet 2013). Durante la primera década del siglo XXI, la tasa de admisión de malienses subió espectacularmente del $0.1 \%$ al 75\%. A pesar de que Malí era en ese momento un de los países más pacíficos y democráticos del continente africano, gracias a esta nueva jurisprudencia sus ciudadanos tuvieron proporcionalmente el mayor índice de aceptación de solicitudes de asilo en Francia - respectivamente, doce y setenta y cinco veces más que en el caso de los turcos y bangladesíes, países donde los miembros de Partido de los Trabajadores del Kurdistán y de la Liga Awami eran víctimas de violencia política. La mayoría de los solicitantes que se acogieron a esta jurisprudencia pertenecen a países musulmanes del África occidental. El segundo tema, la orientación sexual, quedó establecido en 1999 tras un primer caso de homofobia que había sido rechazado seis años antes (Kobelinsky 2012). Basándose en el mismo razonamiento que la persecución por opiniones políticas, la definición del grupo social implicaba que el solicitante de asilo había reconocido su homosexualidad y lo expresaba en su comportamiento. La mayoría de los solicitantes provenían de países musulmanes en el norte de África, Oriente Medio y Asia central.

Ambos grupos sociales — niñas en riesgo y sus padres, gays y lesbianas- se beneficiaron en Francia de la benevolencia de la administración del asilo, especialmente cuando se les compara con personas perseguidas razones políticas, religiosas o étnicas. En la corte, las audiencias de los primeros se hacen frecuentemente a puerta cerrada con pocas preguntas, en marcado contraste con los interrogatorios públicos, largos y duros de los segundos, y las decisiones finales son mucho más favorables 
en el primer caso que en el segundo. Con esta redefinición de las fronteras del asilo, un solicitante tiene una probabilidad significativamente mayor de obtener el estatus de refugiado si alega que tiene una hija en peligro de ser circuncidada ritualmente que si la petición se refiere al riesgo de ser asesinado como opositor político, o si alega que es perseguido por su orientación sexual que si lo hace por ser miembros de una minoría oprimida.

Esta valoración del privilegio del género y de aspectos sexuales sobre formas tradicionales de opresión apunta a un cambio en las jerarquías morales, en las que ciertas violaciones de los derechos humanos son más valoradas que otras. Las solicitudes de los refugiados tienden así a enfocarse en persecución relacionada con la intimidad, lo que abre un nuevo espacio de justificación del asilo, en paralelo al declive de las solicitudes relacionadas con violencia política, religiosa o étnica. De hecho, la introducción de conceptos como "mutilación genital femenina", "matrimonio forzoso", "tráfico sexual" y "homofobia" forma parte de una preocupación internacional más amplia con la discriminación que implica el género y la orientación sexual. Pero esta defensa del género y de la democracia sexual no puede aislarse de un contexto en el que los países occidentales, y Francia en particular, se representan como defensores de los valores universales, especialmente igualdad y laicidad, en que el supuesto choque de civilizaciones se convierte en una confrontación sobre género y asuntos sexuales.

La generosidad de la protección ofrecida a víctimas de estas formas de discriminación consigue dos cosas. En primer lugar, radicaliza la representación de los otros como incivilizados y no democráticos. La excisión es bárbara, la homofobia perversa. Los africanos que practican la primera demuestran su retraso. Los musulmanes que practican la segunda exhiben su intolerancia. En segundo lugar, pone en valor la magnanimidad del mundo occidental como promotor de los derechos de las mujeres y de la democracia sexual, al mismo tiempo que desvía la atención del descenso dramático en la concesión de asilo a las personas que lo solicitan bajo criterios raciales, étnicos, nacionales, religiosos o políticos y, de una manera más amplia, de la actitud cada vez más despectiva y hostil de los gobiernos frente a los inmigrantes. Esta ambigua combinación entre la descalificación de "ellos" y la valoración de "nosotros" se corresponde con los que Éric Fassin (2010: 511) denomina las "políticas sexuales del ser francés" —en este caso aplicada al derecho al asilo.

\section{PARADOJA}

Sorprendentemente, para los que deciden sobre los solicitantes, lejos de señalar un declive en la noción de asilo, esta variaciones y contradicciones múltiples en la implementación real de este principio lo fortalecen. Mientras que un análisis superficial de la economía moral del asilo basado en el análisis de los discursos públicos, el estudio de las estadísticas de aprobación de solicitudes y la observación de los agresivos interrogatorios de los solicitantes durante los procesos legales podría sugerir una muerte progresiva de los ideales plasmados en la Convención de Ginebra de 1951, para los agentes involucrados en este proceso la verdad es justamente lo contrario: están íntimamente convencidos de que defiende estos ideales con ardor. De hecho, 
cuantas más sospechas sobre las reclamaciones y las evidencias del miedo a ser perseguidos despliegan los funcionarios y jueces a cargo de la solicitudes, más valor se le añade al principio abstracto del asilo (Fassin y Kobelinsky 2012). La alta proporción de rechazos, en lugar de hacerles cuestionar los límites de la protección que ofrece la Convención de Ginebra, refuerza sus virtudes. Mediante una paradoja que es sólo aparente, cuanto más descrédito caiga sobre los solicitantes de asilo, más gana en valor el propio asilo. Cuanto menos se conceda, más precioso se vuelve su estatus. Este mecanismo de justificación es particularmente eficaz porque establece simultáneamente el valor del asilo y el mérito de su trabajo de selección. Además, en ocasiones es el asesor que representa al Alto Comisionado de las Naciones Unidas para los Refugiados (ACNUR) el que se muestra más inquisitorial en las audiencias y más inflexible en las deliberaciones. Esta institución, encargada de garantizar los derechos de los refugiados, puede resultar también la que convierte este estatus en más inaccesible.

El problema es por lo tanto entender cómo era posible, no hace mucho tiempo, que se justificaran las decisiones cuando casi todas las solicitudes tenían resoluciones favorables y cómo es tan fácil entender, ahora, que la mayoría sean rechazadas. En base a las entrevistas que hicimos con relatores y sobre todo con los magistrados que tenían amplia experiencia en los juzgados, la única opción moral para resolver este enigma es establecer una separación nítida entre valorar el asilo y devaluar a quienes lo solicitan. El proceso de selección de refugiados ha convertido al asilo en un bien escaso. Al crear esta escasez, la institución debe distribuirlo de acuerdo con principios semejantes a la "decisión trágica", es decir, asignando un bien cuya posesión o carencia puede poner a las personas implicadas en riesgo grave (Calabresi y Bobbit 1978). En este caso, para los solicitantes, el estatus de refugiado es realmente vital, porque su obtención da acceso a derechos sociales y su carencia puede poner en peligro su propia existencia. Los relatores y los jueces son conscientes de ello: desde su perspectiva, defienden el asilo como un derecho abstracto, del cual los refugiados son la expresión concreta, e intentan proteger la pureza del primero y la autenticidad de los segundos frente a lo que consideran fraude y abuso.

\section{CONCLUSIÓN}

Las decenas de miles de personas que cruzan el mediterráneo desde África y el Oriente Próximo en busca de protección no han creado una "crisis de refugiados", como se denomina habitualmente: lo que hacen es revelar una situación que ya existe desde hace varias décadas, en concreto, el retiro progresivo de los países europeos de sus compromisos adquiridos con la Convención de Ginebra de 1951. El argumento de que la mayoría de los solicitantes de asilo son inmigrantes económicos que tratan de aprovecharse del sistema no resiste el examen cuidadoso de los hechos, como he tratado de demostrar en este ensayo que analiza la evolución del caso francés en los últimos cincuenta años. Para entender la situación actual, es preciso considerar dos lógicas separadas pero interrelacionadas, con las que el caso francés ilustra un fenómeno europeo más amplio.

La primera lógica corresponde a la economía política de la inmigración. Durante los llamados "Treinta Gloriosos", es decir, las tres décadas de desarrollo económico que 
siguieron a la Segunda Guerra Mundial, la necesidad de mano de obra para reconstruir el país, fuertemente dañado por el conflicto, llevó al fomento de la inmigración laboral. Viviendo muchas veces en condiciones penosas en pensiones o suburbios en la periferia de las ciudades, estos inmigrantes fueron fuertemente explotados tanto en la industria como en la agricultura. Desde 1954 a 1974 la proporción de extranjeros se dobló en Francia, especialmente con la llegada de españoles y portugueses que escapaban tanto de la pobreza como de la dictadura. Durante esos años, las autoridades no estaban muy interesadas en distinguir entre inmigrantes económicos y solicitantes de asilo. El número de refugiados a mediados de los años cincuenta representaba más de un cuarto de los extranjeros que vivían en Francia: 420.000 de un total de 1.5 millones. Pero con la llamada crisis económica y el cierre de fronteras, la situación cambió drásticamente, y los inmigrantes se convirtieron en indeseados. Las medidas que dificultaban su entrada e incluso la renovación de sus documentos eran cada vez más draconianas, independientemente de su situación personal o familiar. Los solicitantes de asilo, cuyo número iba creciendo, se convirtieron pronto en amenazas, todavía más cuando empezaron a venir del Tercer Mundo, especialmente del continente africano, que estaba sometido a sequía, empobrecimiento y conflictos. Ya sin utilidad como fuerza de trabajo, se convirtieron en sospechosos. A pesar de que durante treinta años habían sido bienvenidos por ser inmigrantes económicos, pasaron a ser dudosos precisamente por lo mismo: porque se les consideraba inmigrantes económicos. Actualmente, los refugiados representan menos de una veinteava parte de todos los extranjeros viviendo en Francia: 170.000 de un total de 3.9 millones.

La segunda lógica se refiere a la economía moral del asilo. No tiene que ver con la producción de riqueza económica sino con la producción de sentimientos y normas morales. Durante las décadas de expansión económica, las normas establecidas en la Convención de Ginebra de 1951 se podían aplicar con generosidad mientras que los sentimientos movilizados oscilaban entre la compasión y la admiración, dependiendo de si los solicitantes de asilo eran concebidos como víctimas o héroes. A medida que el control migratorio empezó a ser aplicado de manera más estricta, la sospecha se convirtió en la nueva norma, desembocando en un giro radical en la evaluación de la evidencia: los solicitantes tenían antes el beneficio de la duda; ahora tienen que probar su caso más allá de toda duda razonable. En paralelo, los sentimientos dominantes se han transformado en indiferencia en el mejor de los casos y hostilidad en el peor, mientras que la empatía residual se moviliza hacia causas específicas, fundamentalmente aquellas relacionadas con el género y la orientación sexual. Una vez que ha perdido su valor económico, los solicitantes de asilo han perdido progresivamente su valor moral. De repente, se les consideraba inmigrantes indocumentados, una condición que efectivamente sería la suya en la práctica, al menos para la gran mayoría de los que ven rechazadas su peticiones.

Cuando se trata de interpretar las tendencias contemporáneas del asilo en Europa, hay que diferenciar y al mismo tiempo relacionar la política económica de la inmigración y la economía moral de asilo. Esto, sin embargo, se hace muy poco. Por un lado, el discurso de las autoridades establece que la economía moral del asilo y la política económica de la inmigración son totalmente autónomos. Es preciso controlar las fronteras, y al mismo tiempo proteger a los refugiados: esa es la versión oficial proclamada repetidamente. El único modo de ajustar este discurso con la rea- 
lidad sobre el terreno es postular que la mayoría de los solicitantes de asilo son en realidad inmigrantes económicos, y que esa es la razón por la que se rechazan sus solicitudes. Por otro lado, el discurso de las organizaciones de derechos humanos combina inextricablemente la economía moral del asilo y la política económica de la inmigración. Funcionarios y magistrados rechazan solicitudes porque se les exige que contribuyan a las políticas de control del flujo demográfico a través de las fronteras: este es el leitmotiv de las protestas. Esta lectura asume la duplicidad de estos agentes, que estarían aprobando solicitudes de acuerdo con criterios ajenos al asilo. La primera interpretación contradice los hechos, como se ha demostrado. La segunda no se corresponde con lo que hemos observado sobre el terreno, ya que la mayoría de los funcionarios y magistrados entrevistados están genuinamente persuadidos de que están tomando las decisión correcta cuando aceptan o rechazan una solicitud. La pregunta es la siguiente: ¿cómo dar cuenta del hecho de que antes estaban convencidos de hacer lo correcto cuando otorgaban el asilo a más de nueve de cada diez solicitantes, y que hoy en día estén satisfechos con la imparcialidad de su juicio cuando rechazan el asilo a ocho de cada diez solicitantes, a pesar de que los relatos que se contaban no eran más creíbles en el pasado y que los demandantes están ahora obligados a proporcionar más evidencia que nunca antes?

Para responder a esta pregunta, hay que distanciarse tanto de las justificaciones del gobierno como de las interpretaciones de los activistas. Ninguna de ellas es totalmente falsa, pero son definitivamente insuficientes. Probablemente, hay solicitudes falsas - como las había antaño. Y ciertamente, los políticos han manipulado datos sobre los solicitantes — para justificar así sus medidas restrictivas. La economía moral del asilo permite al analista ir más allá de justificaciones indulgentes e interpretaciones conspirativas. Puede dar cuenta de por qué funcionarios y magistrados pueden estar convencidos de defender un ideal abstracto al mismo tiempo que desacreditan a aquellos que recurren a él, y por qué la sociedad en general puede adherirse intelectual y emocionalmente a esta visión, según la cual Francia continúa siendo la patria de los derechos humanos, al tiempo que rechaza y a veces deporta solicitantes de asilo por falta de confianza en su relato o en ellos mismos. Es en esta discrepancia entre palabras y actos, entre el lenguaje oficial de los derechos y las prácticas reales de exclusión, y en su justificación a través del descrédito de los solicitantes y la descalificación de sus demandas que se desvela la situación actual de los refugiados en Europa. Cada vez es más difícil ignorar el hecho de que la mayoría de ellos vienen de países como Siria, Irak, Somalia, Sudán o Eritrea, donde la persecución y violencia políticas son innegables. Así la cruda verdad del rechazo europeo a respetar sus compromisos internacionales sale a plena luz.

\section{RECONOCIMIENTOS}

Aunque este ensayo es original, obviamente usa materia y analisis que han sido desarrollados en los tres artículos que menciono en las referencias. Agradezco a Liliana Suárez-Navaz y Paco Ferrándiz por su excelente traducción. 


\section{BIBLIOGRAFÍA CITADA}

Benveniste, Émile. 1969. Vocabulaire des institutions indo-européennes 1: Économie, parenté, société. Paris: Éditions de Minuit.

Calabresi, Guido y Philip Bobbit. 1978. Tragic Choices. The Conflicts Society Confronts in the Allocation of Tragically Scarce Resources. Nueva York: Norton.

Cholet, Guillaume. 2013. "Droit d'asile: Le Conseil d'Etat aux prises avec les mutilations genitals", Revue des Droits de l'Homme, Lettres Actualités Droits-Libertés. Disponible en: <http://revdh.org/2013/02/ 18/droit-dasile-conseil-detat-mutilations-genitales-feminines/>. Fecha de acceso: 06 oct. 2015.

Daniel, Valentine y John Chr. Knudsen (eds.). 1995. Mistrusting Refugees. Berkeley: University of California Press.

Daston, Lorraine. 1995. "The Moral Economy of Science". Osiris 10: 2-24.

Fassin, Didier. 2009. "Les économies morales revisitées". Annales. Histoire, Sciences Sociales 64(6): 1237-1266.

Fassin, Didier. 2013. "The Precarious Truth of Asylum". Public Culture 25(1): 39-63.

Fassin, Didier y C Kobelinsky. 2012. "How Asylum Claims are Adjudicated: The Institution as Moral Agent. Revue Française de Sociologie 53(4): 444-472.

Fassin, Éric. 2010. National Identities and Transnational Intimacies: Sexual Democracy and the Politics of Democracy in Europe. Public Culture 22(3): 507-529.

Foucault, Michel. 2001. «Polémique, politique et problématisations", en Dits et écrits, volume 2: 14101417. Paris: Gallimard.

Fustel de Coulanges, Numa Denys. 1900 [1864]. La cité Antique. Paris: Hachette.

Halluin-Mabillot, Estelle d'. 2012. Les épreuves de l'asile. Associations et réfugiés face aux politiques du soupçon. Paris: Éditions de l'EHESS.

Kelly, Tobias. 2012. "Sympathy and Suspicion. Torture, Asylum, and Humanity". Journal of the Royal Anthropological Institute 18: 753-768.

Kobelinsky, Carolina. 2012. "L'asile gay: Jurisprudence de l'intime à la Cour nationale du droit d'asile". Droit et Société 82: 583-601.

Marrus, Michael R. 1985. The Unwanted. European Refugees from the First World War Through the Cold War. Nueva York: Oxford University Press.

Noiriel, Gérard. 1991. La tyrannie du national. Le droit d'asile en Europe, 1793-1993. Paris: CalmannLévy.

OFPRA. 2010. De la Grande guerre aux guerres sans nom. Une histoire de l'Ofpra. Fontenay-sousBois: Office français de protection des réfugiés et des apatrides,

OFPRA, 2011. Rapport d'activité. Fontenay-sous-Bois: Office français de protection des réfugiés et des apatrides.

Say, Jean-Baptiste. 1972 [1803]. Traité d'économie politique ou simple exposition de la manière dont se forment, se distribuent ou se consomment les richesses. Paris: Calmann-Lévy.

Scott, James. 1976. The Moral Economy of the Peasant: Rebellon and Subsistence in Southeast Asia. New Haven: Yale University Press.

Spire, Alexis. 2004. "Les réfugiés, une main d'oeuvre à part? Conditions de séjour et d'emploi, France, 1945 1975". Revue Européenne des Migrations Internationales 20(2): 1338.

Thompson, Edward P. 1968. The Making of the English Working Class. Londres: Penguin Books.

Thompson, Edward P. 1971. "The Moral Economy of the English Crowd in the Eighteenth Century. Past and Present 50: 76-136.

UNHCR/ACNUR. 2011. Convention and Protocol Relating to the Status of Refugees. Ginebra: UN High Commissioner for Refugees. 